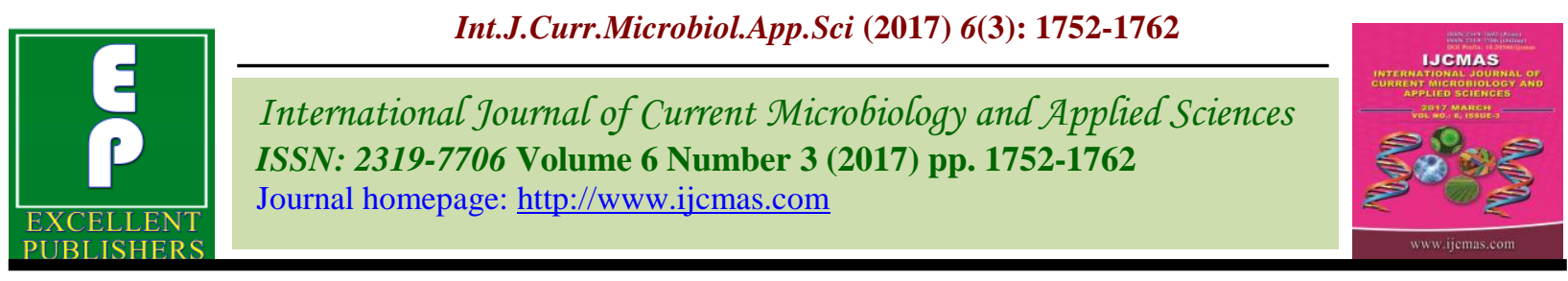

Original Research Article https://doi.org/10.20546/ijcmas.2017.603.201

\title{
Isolation and Identification of Two Potassium Solubilizing Fungi from Arid Soil
}

\author{
Ramesh Chand Kasana*, Nav Raten Panwar, Uday Burman, \\ Chandra Bhushan Pandey and Praveen Kumar
}

\author{
ICAR-Central Arid Zone Research Institute, Jodhpur-342003, India \\ *Corresponding author
}

\section{A B S T R A C T}

\begin{tabular}{|c|c|}
\hline Key & anisms were isolated from the arid soil of Jodhpur, \\
\hline $\begin{array}{l}\text { Potassium } \\
\text { solubilizing, } \\
\text { Fomitopsis, } \\
\text { Aspergillus, } \\
\text { Feldspar, Arid soil }\end{array}$ & $\begin{array}{l}\text { India. Among them two fungal isolates RCKF7 followed by RCKF5 showed higher } \\
\text { dissolution capacity towards feldspar, resulting in the release of more potassium compared } \\
\text { to the others. Based on morphological characters and sequencing of ITS1-5.8S-ITS2 } 2 \\
\text { region the strains were identified as Fomitopsis meliae RCKF7 and Aspergillus tubingensis } \\
\text { RCKF5. On further screening of the more potent strain RCKF7, it showed its ability to }\end{array}$ \\
\hline Artic & \\
\hline $\begin{array}{l}\text { Accepted: } \\
\text { 24 February } 2017 \\
\text { Available Online: } \\
\text { 10 March } 2017\end{array}$ & $\begin{array}{l}\text { Capability of RCKF7 to solubilize phosphorus also rendered it an additional advantage. } \\
\text { Furthermore the application of } 500 \mathrm{ppm} \text { and } 1000 \mathrm{ppm} \text { feldspar alone or in combination } \\
\text { with RCKF7 resulted in more grain yield in wheat as compared to recommended dose of } \\
\text { potassium fertilizer. }\end{array}$ \\
\hline
\end{tabular}

\section{Introduction}

After nitrogen (N) and phosphorus (P), potassium $(\mathrm{K})$ is the third major essential macronutrients playing a key role in the growth and development of plants. In the world large areas of the agricultural land are deficient in potassium including three-fourth of the paddy soils of China and two-third of the wheat belt of Southern Australia (Meena et al., 2014). The studies carried out on fertility status of Indian agricultural soils however, have shown that $21 \%$ of soils are low, $51 \%$ medium and $28 \%$ high in potassium. Hence about three-fourth agricultural soils require immediate attention (Hasan, 2002 and Meena et al., 2016). As most of the potassium requirements in India is met through the imported fertilizer and with price varying between $\$ 460-625$ per tonne this makes it a costly proposition. In the year 2009-10, India consumed 55.10 lakh tonnes of murate of potash) of which 42.38 lakh tonnes was used as fertilizer (Kinekar, 2011). It has been also projected that to meet the food demand of 1.3 billion Indians by 2020 the requirement of potassium by Indian agriculture would be 9.52 Mt (Pathak et al., 2010). Also very low percentage of potassium present in the soil either naturally or when applied as synthetic fertilizers is available to plants as most of it is bound with other minerals, and is therefore unavailable to the plants (Goldstein, 1994 and Prajapati et al., 2013). To increase the availability of potassium for plants, huge quantities of 
fertilizer are applied in the field on a regular basis. However, after application in the field a major proportion of these fertilizers is transformed to the insoluble forms necessitating continuous application (Kang et al., 2002). Thus, the release of potassium from insoluble and fixed forms is an important aspect for increasing its availability in soil. The modification of various rock minerals in natural environments is mainly carried out by the action of water and organic acids produced by plant roots and microorganisms. Various potassium solubilizing microorganisms like Bacillus, Enterobacter, Pseudomonas and Aspergillus have been isolated and employed for their beneficial effect on plant growth promotion (Bagyalakshmi et al., 2012; Prajapati et al., 2013; Zhang and Kong, 2014 and Anjanadevi et al., 2016). The different microorganisms and minerals from which they can release potassium have been reviewed recently (Sharma et al., 2016). Large resources of good quality feldspar (8-10\% potassium) in Rajasthan, India, could also be effectively utilized by native potassium solubilizing microorganisms. Therefore the present work was conducted to isolate and test feldspar solubilization by strains from arid soil and to assess its response on growth of wheat.

\section{Materials and Methods}

\section{Isolation and purification of microorganisms from arid soil}

Soil samples were collected from different locations in the arid environment of ICARCentral Arid Zone Research Institute, Jodhpur in 2014. Ten-fold serial dilutions of soil samples were prepared in sterilized distilled water, and $0.1 \mathrm{~mL}$ of diluted samples was spreaded on the surface of nutrient agar $(0.3 \%$ beef extract, $0.5 \%$ peptone, $0.5 \% \mathrm{NaCl}$, and $1.7 \%$ agar) and potato dextrose agar (20\% potatoes, $2 \%$ dextrose, $1.7 \%$ agar) (HiMedia,
India) for isolation for bacteria and fungi (Kasana et al., 2008). Plates were incubated at $28^{\circ} \mathrm{C}$ for 48 hours for bacteria and $96-120$ hours for fungi. Morphologically different colonies appearing on the plates were purified on the respective medium for bacteria and fungi.

\section{Screening of microorganisms for potassium solubilization}

The microorganisms were screened for potassium solubilizing activity on Aleksandrov agar medium (Hu et al., 2006) having: $0.5 \%$ glucose, $0.05 \%$ magnesium sulfate heptahydrate, $0.0005 \%$ iron chloride, $0.01 \%$ calcium carbonate, $0.2 \%$ calcium phosphate, $0.2 \%$ feldspar (potassium aluminum silicate) and $1.8 \%$ agar; by spot plate method.

\section{Identification of fungal isolates}

Morphological studies were conducted by growing the strains on potato dextrose agar plates and incubating at $28{ }^{\circ} \mathrm{C}$. The visual and microscopic examination of the fungal growth was conducted. For molecular identification the fungal strains RCKF5 and RCKF7 were cultivated in $100 \mathrm{~mL}$ of liquid medium at 28 ${ }^{\circ} \mathrm{C}$ under continuous agitation at $150 \mathrm{rpm}$. Mycelia from 96 hour grown cultures harvested and DNA was extracted. The DNA was amplified by using ITS1 (5'-TCC GTA GGT GAA CCT GCG G-3') and ITS 4 (5'TCC TCC GCT TAT TGA TAT GC-3') primers. The PCR was initiated by incubating the reaction mixture at $94^{\circ} \mathrm{C}$ for $3 \mathrm{~min}$, followed by 35 cycles of $1 \mathrm{~min}$ at $94{ }^{\circ} \mathrm{C}$. The reaction was annealed at $55{ }^{\circ} \mathrm{C}$ for $1 \mathrm{~min}$ and terminated with extension and final steps consisting of $1 \mathrm{~min}$ at $72{ }^{\circ} \mathrm{C}$ and $10 \mathrm{~min}$ at 72 ${ }^{\circ} \mathrm{C}$. The amplified gene products were electrophoresed on 1.2\% agarose gel and desired band of about 600 bp was excised and purified using Qiaquick Gel Extraction Kit 
(Qiagen, Germany). Nucleotide sequencing of the genes was done by using Big Dye Terminator Cycle Sequencing Kit (Applied Biosystems) and 3130xl Genetic Analyzer (Applied Biosystems). The BLASTN program http://www.ncbi.nlm.nih.gov/BLAST/;

National Center for Biotechnology Information, Bethesda, MD) was used for homology searches with the standard program default.

\section{Assessment of potassium solubilization potential of isolates}

Effect of temperature and $\mathrm{pH}$ on potassium solubilization

To check the effect of temperature on potassium solubilization the fungal culture was inoculated on Aleksandrov agar medium and plates were incubated at three different temperatures 20, 28 and $38{ }^{\circ} \mathrm{C}$ in $\mathrm{BOD}$ incubator. To study the effect of $\mathrm{pH}$ on potassium solubilization Aleksandrov agar medium plates of varying $\mathrm{pH}$ ranging from 5.0 to 10.0 were prepared and inoculated with culture. Plates were incubated at $28{ }^{\circ} \mathrm{C}$ and 38 ${ }^{\circ} \mathrm{C}$ in BOD incubators. Solubilization index was calculated using the formula given below

\section{Solublizing index $=$ \\ Colony diameter + clearing zone Colony diameter}

\section{Quantitative estimation of potassium solubilization}

Feldspar was added to the liquid Aleksandrov medium as the sole potassium source to test the ability of the isolate to solubilize it. Quantitative estimation of potassium solubilization was carried out in Erlenmeyer flasks containing $100 \mathrm{~mL}$ of Aleksandrov medium, and inoculated in triplicate with RCKF7. Autoclaved, uninoculated medium served as controls. The flasks were incubated at $38{ }^{\circ} \mathrm{C}$ in a BOD incubator. The supernatant obtained by filtering the culture using Whatman filter number 42 was used to assay the solubilized potassium using atomic absorption spectrometry (Manib et al., 1986).

\section{Pot experiment}

The fungus RCKF7 was grown in potato dextrose broth for 7 days. Four gram of wet mycelium was crushed in $100 \mathrm{~mL}$ of water. The plastic pots $(22 \mathrm{~cm}$ top diameter, $14 \mathrm{~cm}$ bottom and $22 \mathrm{~cm}$ height) were filled @ $5 \mathrm{~kg}$ pot $^{-1}$ sandy soil $(\mathrm{pH} \quad 8.4$, electrical conductivity $0.29 \mathrm{dS} \mathrm{m}^{-1}$, organic carbon 2.1 $\mathrm{g} \mathrm{kg}^{-1}$, available $\mathrm{N} 94.5 \mathrm{~kg} \mathrm{ha}^{-1}$, available $\mathrm{P}$ $10.60 \mathrm{~kg} \mathrm{ha}^{-1}$, available $\mathrm{K} 236 \mathrm{~kg} \mathrm{ha}^{-1}$ and available sulfur $8.66 \mathrm{ppm}$.

Feldspar was added to the soil in pots as per the treatments and thoroughly mixed. Seeds of wheat were soaked in the water containing the crushed mycelium for 30 minutes and seven seeds were sown $2 \mathrm{~cm}$ deep in each pot. Performance of wheat was assessed under following nine treatments with three replications. Soil alone, soil + recommended dose of NP, soil + recommended dose of $\mathrm{NPK}$, soil + recommended dose of NP + 250 ppm Feldspar, soil + recommended dose of $\mathrm{NP}+500$ ppm Feldspar, soil + recommended dose of NP +1000 ppm Feldspar, soil + recommended dose of $\mathrm{NP}+250 \mathrm{ppm}$ Feldspar + RCKF7, soil + recommended dose of NP + 500 ppm Feldspar + RCKF7 and soil + recommended dose of $\mathrm{NP}+1000 \mathrm{ppm}$ Feldspar + RCKF7.

The pots were irrigated at regular interval and after 15 days of germination plants were thinned to five plants per pot. The rate of net photosynthesis was measured in two uppermost fully expanded leaves of intact plants using CIRAS-2 portable photosynthesis system. The measurements were made on 
three plants in each treatment between 10-12 hour at 67 days of sowing. In vivo estimation of nitrate reductase activity using leaf disc from same leaves was done following the method of Jaworski, 1971. The crop was harvested after 93 days of sowing and data of dry shoot weight, weight of spikes and grain yield per pot were recorded.

\section{Screening of potassium solubilizing microoganisms for phosphate solubilization}

Potassium solubilizing isolate RCKF7 was also screened for phosphate solubilizing activity on Pikovskaya's medium: 1.0\% glucose, $0.5 \%$ tricalcium phosphate, 0.05 ammonium sulphate, $0.02 \%$ potassium chloride, $0.01 \%$ magnesium sulfate heptahydrate, traces of manganese sulphate and iron sulphate, $0.05 \%$ yeast extract and 1.8\% Agar (Himedia) by spot inoculation. A clear zone around the colony indicated the potassium and phosphate solubilization.

\section{Results and Discussion}

\section{Isolation and purification of microorganisms from arid soil}

Twenty five bacterial and fifteen fungal isolates were selected and purified based on morphological characteristics from arid environment soil samples collected from Jodhpur. Among these isolates three fungal and two bacterial isolates showed potassium solubilization.

Results suggest the existence of potassium solubilizing fungi in desert soil environments. Potassium solubilization on mica powder containing medium plates have been reported earlier (Parmar and Sindhu, 2013).

Potassium solubilizing isolates from various rhizospheric soils samples have also been reported from Inceptisol and Alfisol (Maurya et al., 2014).
Screening of microorganisms for potassium solubilizations

Strains RCKF7 followed by RCKF5 which formed larger zone of clearance on Aleksandrov agar medium were selected as potent potassium solubilizer and used for further studies (Fig. 1).

\section{Identification of fungal isolates}

The culture on potato dextrose agar showed white mycelium for two-three days which became black as conidia develop in case of RCKF5. The guttulate hyphae and uniserate conidiophores indicated its affiliation to genus Aspergillus. Based on morphological characters the strain RCKF7 was identified as belonging to genus Fomitopsis (Kang et al., 2002). The upper surface of colonies appeared white on potato dextrose agar which was also white on the reverse side, pigment absent. The texture of the colonies on potato dextrose agar was powdery with velvety appearance. Spore formation did not occur on potato dextrose agar after prolonged incubation (Fig. 1). Further identification and phylogenetic relationship studies of RCKF7 and RCKF5 were conducted based on the sequenced ITS1-5.8S-ITS2 region. The sequences were also submitted to NCBI with accession numbers KT718002 and KT718003 respectively. In case of RCKF5 a homology of $99.83 \%$ was found with Aspergillus tubingensis strain CBS 134.48 with a published species in literature (Accensi et al., 1999). In case of RCKF7 a homology of 97.7\% was found with Fomitopsis meliae voucher SRM-209 with a published species in the literature (Ortiz-Santana et al., 2013). Though, RCKF7 showed homology of only $97.7 \%$ but was identified as Fomitopsis meliae RCKF7, it may represent new species of genus Fomotopsis. The sequences of the isolate were then aligned and compared with previously published sequences of the species 
from genus Fomitopsis and Aspergillus with published names, and neighbor-joining phylogenetic trees were constructed using MEGA6 (Tamura et al., 2013). In phylogenetic analysis the strain RCKF7 clustered with Fomitopsis meliae SRM-209KC585351 (Fig. 2a) whereas, in case of the strain RCKF5, it clustered with Aspergillus tubingensis CBS 134.48 AJ223853 (Fig. 2b). Though bacteria belonging to various genera have been reported for solubilization of potassium, however in case of fungi the strains belonging only to the genus Aspergillus (Lopes-Assad et al., 2010), have been reported for solubilization of potassium. Mostly, Fomitopsis species have been isolated as endophytes from various sources like Fomitopsis cf. meliae, $F$. cf. ostreiformis, $F$. cf. pinicola were isolated from the oil palm, Elaeis guineensis, at an oil palm plantation in Trang Province, Thailand (Rungjindamai et al., 2008 and Pinruan et al., 2010), Fomitopsis cf. meliae isolated from the Bacopa monnieri (Katoch et al., 2014), but Fomitopsis sp. PS 102 was isolated from the ground soil at Taegu, South Korea (Kang et $a l ., 2002)$. The strains belonging to genus Fomitopsis have been reported for phosphate solubilizing ability and potent cytotoxic and antimicrobial properties (Kang et al., 2002 and Katoch et al., 2014), but this is first report on potassium solubilization by fungi belonging to genus Fomitopsis.

\section{Potassium solubilization at different temperatures and pHs}

Fomitopsis meliae RCKF7 was isolated from desert soil and has the ability to grow and solubilize potassium over wide range of temperature and $\mathrm{pH}$. Fomitopsis meliae RCKF7 was grown at different temperatures on Aleksandrov agar medium for solubilization of potassium. It showed highest growth and larger clearing zone at $38{ }^{\circ} \mathrm{C}$ followed by $28{ }^{\circ} \mathrm{C}$ and $20{ }^{\circ} \mathrm{C}$ (Fig. 3). This reflects the adaptability of the isolate to wide range of temperature that also naturally occurs in arid soils. The maximum solubilization index was observed at $28{ }^{\circ} \mathrm{C}$ followed by $38{ }^{\circ} \mathrm{C}$ and $20{ }^{\circ} \mathrm{C}$ and (Fig. 4). Among various bacterial strains isolated from rhizosphere soil of wheat two strains WPS73 and NNY43 showed maximum potassium solubilization at 25 and $30{ }^{\circ} \mathrm{C}$ respectively, whereas other bacterial strains showed significant solubilization in the temperature range of $25{ }^{\circ} \mathrm{C}$ to $35^{\circ} \mathrm{C}$ (Parmar and Sindhu, 2013).

The quantative estimation of potassium release from feldspar source at $38{ }^{\circ} \mathrm{C}$ using atomic absorption spectrometry was estimated to be $7.1 \mathrm{mg} \mathrm{L}^{-1}$. Studies conducted recently on potassium solubilization have shown that potassium release from feldspar ranged from 0.13 to $12.25 \mathrm{mg} \mathrm{L}^{-1}$ by different microbial isolates (Setiawati and Mutmainnah, 2016).

As most of the fungal isolates generally prefer acidic $\mathrm{pH}$ for their growth hence to observe the effect of $\mathrm{pH}$ on $\mathrm{K}$ solubilization strain RCKF7 was inoculated on Aleksandrov agar plates of different $\mathrm{pH}$ and incubated at two temperatures of 28 and $38{ }^{\circ} \mathrm{C}$. The fungus showed better growth at acidic $\mathrm{pH} 5$ which declined with increase in the $\mathrm{pH}$, with minimum growth at $\mathrm{pH} 10$ as evident from the colony size (Fig. 4). The solubilization index was observed in the range of 2.06 to 2.15 and at both the temperatures the maximum solubilization index was observed at pH 6 (Fig. 4).

As agriculture is practiced under various agro climatic conditions with lot of variation in temperature and soil parameters, hence strains capable of potassium solubilization under wide range of temperature and $\mathrm{pH}$ have wider applicability. Furthermore, along with potassium solubilization strain RCKF7 also showed the solubilization of phosphorus rendering it an additional advantage. 
Effect of application of feldspar and potassium solubilizing fungus on wheat

Application of feldspar and potassium solubilizing fungi resulted in an increase in shoot dry weight, weight of spikes and grain yield (Table 1). Maximum shoot dry weight of $48.7 \mathrm{~g}$ was obtained with application of $1000 \mathrm{ppm}$ of feldspar, while maximum weight of spikes and grain yield of 22.43 and 15.77 respectively were obtained with application of $500 \mathrm{ppm}$ of feldspar and RCKF7. Application of $500 \mathrm{ppm}$ and $1000 \mathrm{ppm}$ feldspar alone or in combination with RCKF7 resulted in more grain yield as compared to recommended dose of potassium fertilizer (Table 1). This is in line with the earlier report wherein authors reported that use of imbalanced fertilizers, including potash leads to a reduction of soil potash reserves and results in yield losses (Tan et al., 2005). Microorganisms capable of dissolving potassium from mineral and rocks influence the plant growth and have both economic and environmental advantage. Significant increases in yield due to application of potassium solubilizing microorganisms have been also reported in Capsicum annuum (Supanjani et al., 2006) and sudan grass (Basak and Biswas, 2009). This could be either due to more uptake of potassium as in tobacco (Zhang and Kong, 2014) and okra (Prajapati et al., 2013).

Table.1 Effect of feldspar solubilizing fungi RCKF 7on wheat under pot condtions

$\begin{array}{lccc}\text { Treatments } & \begin{array}{c}\text { Shoot dry weight } \\ (\mathrm{g}) / \text { pot }\end{array} & \begin{array}{c}\text { Weight of spikes } \\ (\mathrm{g}) / \text { pot }\end{array} & \begin{array}{c}\text { Grain yield } \\ (\mathrm{g}) / \mathrm{pot}\end{array} \\ \text { Soil (Control) } & 28.53 & 14.00 & 9.50 \\ \text { Soil +NP } & 39.90 & 18.50 & 11.97 \\ \text { Soil +NP+K } & 44.17 & 20.00 & 13.43 \\ \text { Soil+Felds (250ppm)+NP } & 30.93 & 16.93 & 11.73 \\ \text { Soil+Felds (500ppm)+NP } & 46.67 & 22.00 & 15.57 \\ \text { Soil+Felds (1000ppm)+NP } & 48.70 & 21.13 & 14.17 \\ \text { Soil+Felds (250ppm)+RCKF7+NP } & 31.83 & 18.60 & 12.40 \\ \text { Soil+Felds (500ppm)+RCKF7+NP } & 41.90 & 22.43 & 15.77 \\ \text { Soil+Felds (1000ppm)+RCKF7+NP } & 38.63 & 21.40 & 14.90\end{array}$

Fig.1 Pure culture of RCKF7 on a) potato dextrose agar and b and c) potassium solubilization on Aleksandrov agar by RCKF7 and RCKF5 as indicated by hallow formation around the growth

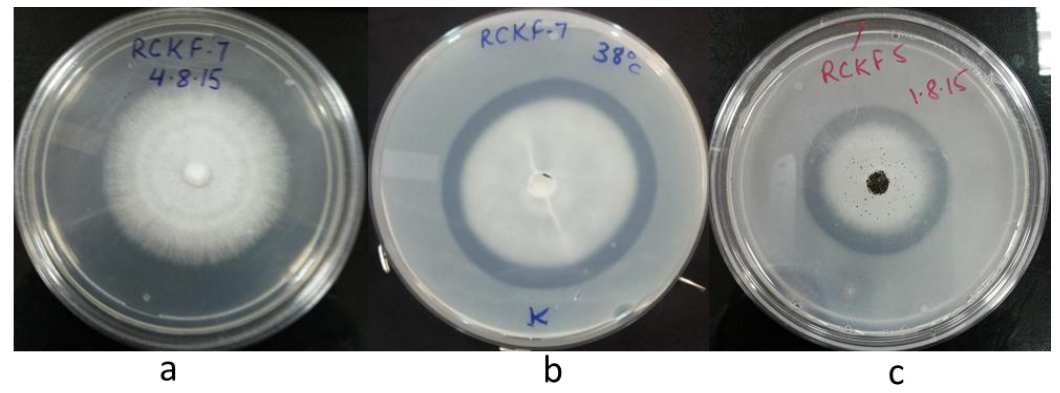


Fig.2a Phylogenetic tree based on ITS1-5.8S-ITS2 region sequences, drawn using the neighbor joining method and showing the relationship between Fomitopsis meliae RCKF7 and species from genus Fomitopsis. The sequences were downloaded from NCBI database. Aspergillus tubingensis was used to root the tree. Bar, 0.1 substitutions per site. Evolutionary analyses were conducted in MEGA6

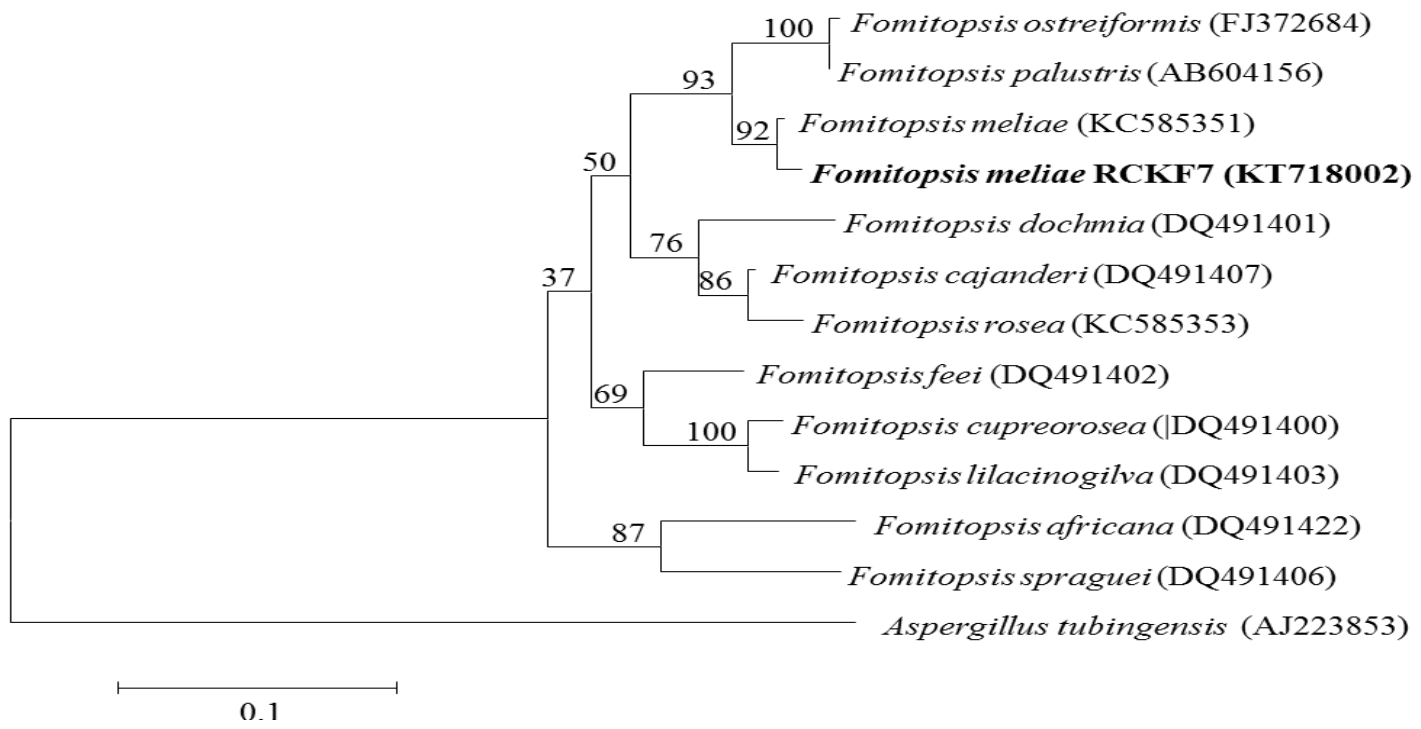

Fig.2b Phylogenetic tree based on ITS1-5.8S-ITS2 region sequences, drawn using the neighbor joining method and showing the relationship between Aspergillus tubingensis RCKF5 and species from genus Aspergillus. The sequences were downloaded from NCBI database. Fomitopsis africana was used to root the tree. Bar, 0.05 substitutions per site. Evolutionary analyses were conducted in MEGA6

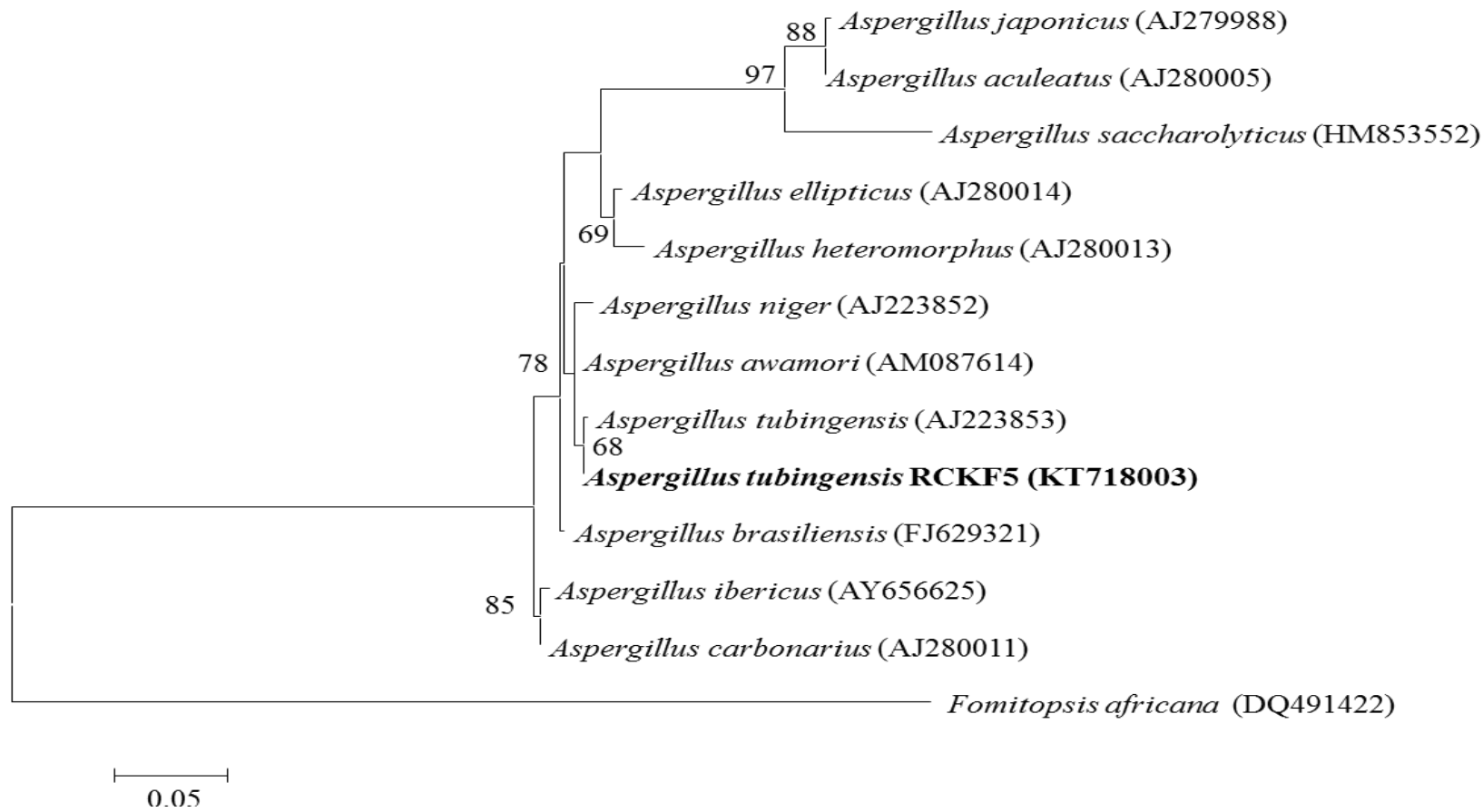


Fig.3 Potassium solubilization by RCKF7 at different temperature

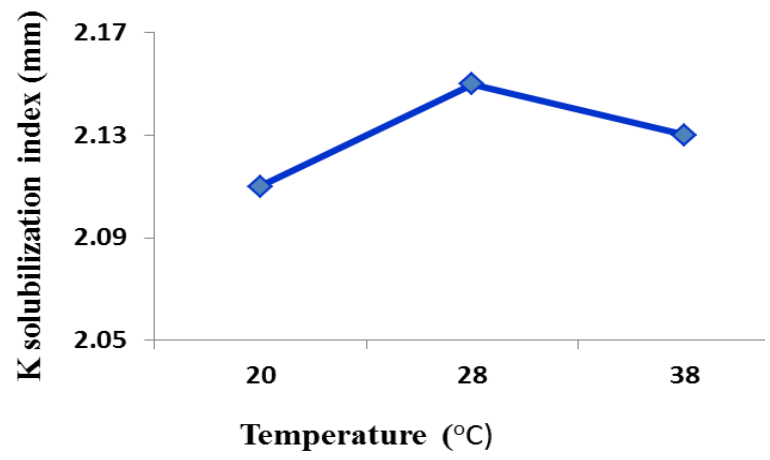

Fig.4 Potassium solubilization by RCKF7 at different $\mathrm{pH}$

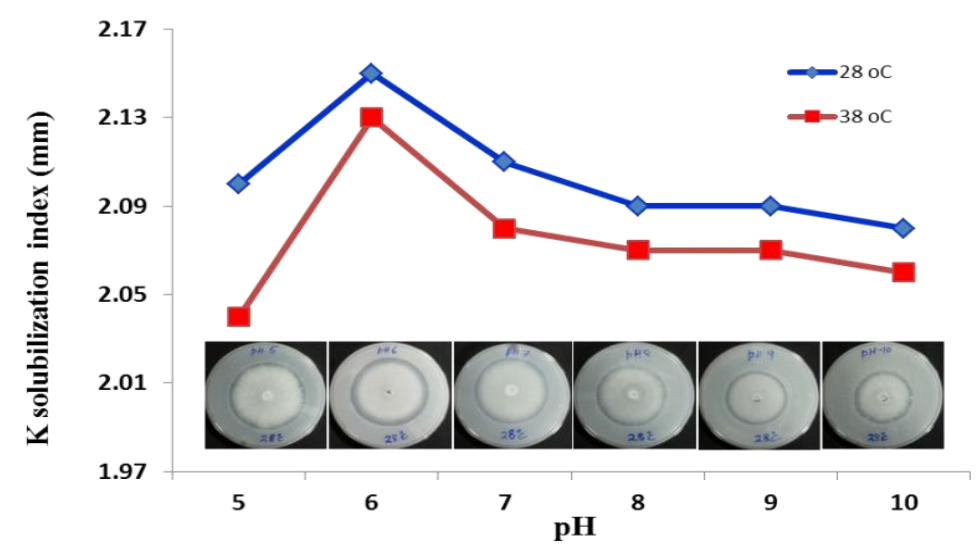

Fig.5 Effect of inoculation with potassium solubilizing fungi RCKF7 on nitrate reductase activity \& photosynthetic rate of wheat under pot conditions

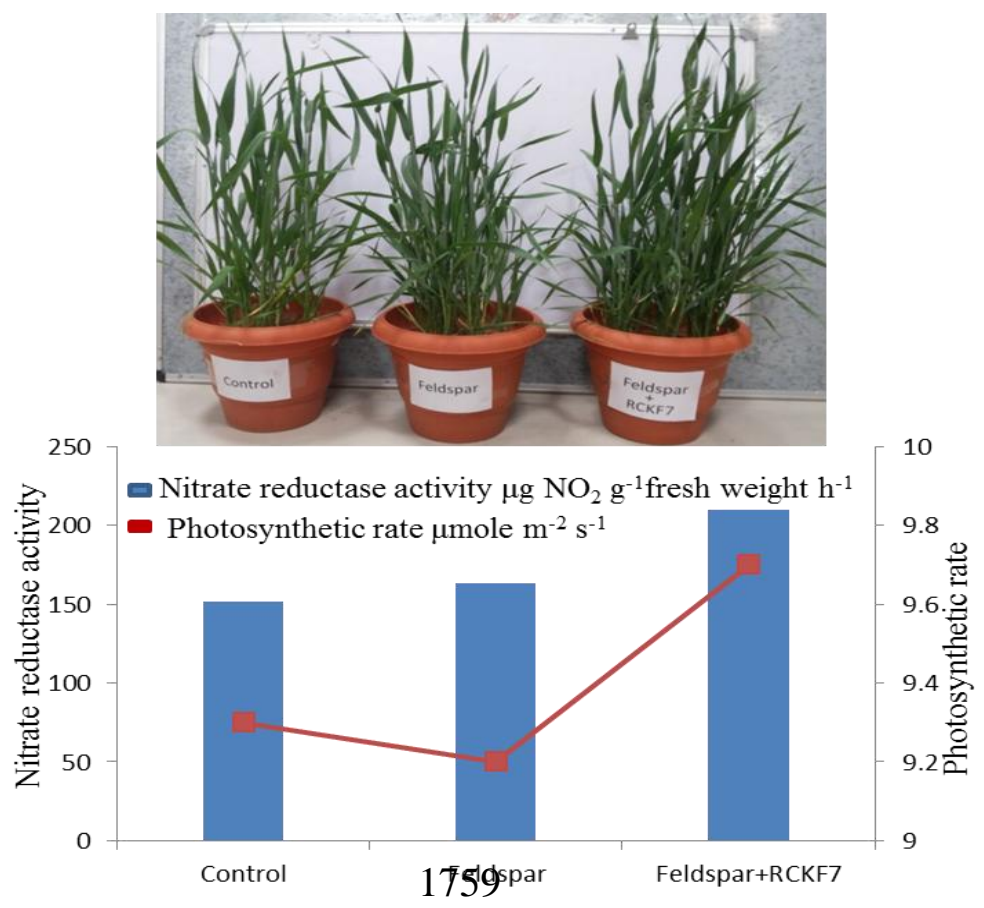


Release of potassium through use of potassium solubilizing microorganisms from feldspar and other minerals rocks provide possibility of potassium solubilization (Hassan, et al., 2010 and Anjanadevi et al., 2016.) In our work better growth under feldspar alone or feldspar along with RCKF7 (Fig. 5) compared to control corroborated with higher nitrate reductase activity and photosynthetic rate (Fig. 5). This could be possibly through regulation of more carbon reduction cycle enzymes besides photorespiration through stomatal activity by potassium (Page et al., 2006). In control inadequate potassium may also adversely affect phloem transport (Cakmak et al., 1994a and 1994b) which in turn limits the carbon supply required for continuous nitrogen assimilation and growth. Nitrate reductase has also been reported to significantly decrease under potassium deficient conditions (Armengaud et al., 2009). Suboptimal level of potassium also results in buildup of photosynthate in leaves due to adverse effect on transport and subsequent reduction in rate of photosynthesis.

In conclusion, this is the first report of solubilization of feldspar by a fungus (RCKF7) belonging to the genus Fomitopsis. Its ability to grow and solubilize feldspar at wide range of temperature and $\mathrm{pH}$ shows that this fungus may serve as good feldspar solubilizer when inoculated into the arid soils where potassium availability is otherwise low due to poor soil structure. In arid zone where resource limited farmers's often overlook importance of potassium and prioritize more in favour of nitrogen and phosphorus, application of feldspar along with potassium solubilizing microorganism is likely to give better yield over a long period.

Further studies needs to be conducted in order to find out the actual level of solubilization while considering the potassium consumed by the fungus and its efficiency in solubilizing the feldspar under field conditions.

\section{Acknowledgements}

Authors acknowledge the Director, ICARCentral Arid Zone Research Institute, Jodhpur for necessary facilities and support. The financial assistance received under the institutional project (CAZRI/T-02/53) is also duly acknowledged.

\section{References}

Accensi, F., Cano, J., Figuera, L., Abarca, M.L., Cabañes, F.J. 1999. New PCR method to differentiate species in the Aspergillus niger aggregate. FEMS Microbiol. Lett., 180(2): 191-196.

Anjanadevi, I.P., John, N.S., John, K.S., Jeeva, M., and Misra, R.S. 2016. Rock inhabiting potassium solubilizing bacteria from Kerala, India: characterization and possibility in chemical $\mathrm{K}$ fertilizer substitution. $J$. Basic Microbiol., 56: 67-77.

Armengaud, P., Sulpice, R., Miller, A.J., Stitt, M., Amtmann, A., Gibon, Y. 2009. Multilevel analysis of primary metabolism provides new insights into the role of potassium nutrition for glycolysis and nitrogen assimilation in Arabidopsis roots. Plant Physiol., 150: 772-785.

Bagyalakshmi, B., Ponmurugan, P., Marimuthu, S. 2012. Influence of potassium solubilizing bacteria on crop productivity and quality of tea. Camellia sinensis). Afr. J. Agric. Res., 7(30): 4250-4259.

Basak, B.B., Biswas, D.R. 2009. Influence of potassium solubilizing microorganism. Bacillus mucilaginosus. and waste mica on potassium uptake dynamics by sudan grass. Sorghum vulgare Pers.. grown 
under two Alfisols. Plant Soi,1 317: 235-255.

Cakmak, I., Hengeler, C., Marschner, H. 1994a. Partitioning of shoot and root dry matter and carbohydrates in bean plants suffering from phosphorus, potassium and magnesium deficiency. J. Exp. Bot., 45: $1245-1250$.

Cakmak, I., Hengeler, C., Marschner, H. 1994b. Changes in phloem export of sucrose in leaves in response to phosphorus, potassium and magnesium deficiency in bean plants. J. Exp. Bot., 45: 1251-1257.

Goldstein, A.H. 1994. Involvement of the quinoprotein glucose dehydrogenase in the solubilization of exogenous mineral phosphates by gram-negative bacteria. In Phosphate in Microorganisms: Cellular and Molecular Biology, eds. Torriani-Gorni A, Yagil E, Silver S. pp. 197-203, Washington: ASM Press.

Hasan, R. 2002. Potassium status of soils in India. Better Crops Int., 16: 3-5.

Hassan, E.A., Hassan, E.A., Hamad, E.H. 2010. Microbial solubilization of phosphate - potassium rocks and their effect on khella. Ammi visnaga. growth. Ann. Agric. Sci. Cairo. 55: 37-53

$\mathrm{Hu}, \quad$ X., Chen, J., Guo, J. 2006. Two phosphate- and potassium-solubilizing bacteria isolated from Tianmu Mountain, Zhejiang, China. World J. Microbiol. Biotechnol., 22(9): 983-990 .

Jaworski, E.G. 1971. Nitrate reductase assay in intact plant tissues. Biochem Biophys Res Commun., 43: 1274-1279

Kang, S.C., Ha, C.G., Lee, T.G. and D.K. Maheshwari. 2002. Solubilization of insoluble inorganic phosphates by a soil-inhabiting fungus Fomitopsis sp. PS 102 Curr. Sci., 82(4): 439-442.

Kasana, R.C., Salwan, R., Dhar, H., Dutt, S., Gulati, A. 2008. A rapid and easy method for the detection of microbial cellulases on agar plates using gram's iodine. Curr. Microbiol., 57: 503-507.

Katoch, M., Singh, G., Sharma, S., Gupta, N., Sangwan, P.L., Saxena, A.K. 2014. Cytotoxic and antimicrobial activities of endophytic fungi isolated from Bacopa monnieri. L.. Pennell. Scrophulariaceae). BMC Complement Altern. Med., 14: 52-60 doi: 10.1186/1472-6882-14-52.

Kinekar, B.K. 2011. Potassium fertilizer situation in India: Current use and perspectives. Karnataka J. Agric. Sci., 24(1): 1-6.

Lopes-Assad, M.L., Avansini, S.H., Rosa, M.M., de Carvalho, J.R., CeccatoAntonini. S.R. 2010. The solubilization of potassium-bearing rock powder by Aspergillus niger in small-scale batch fermentations. Can. J. Microbiol., 56(7): 598-605. doi: 10.1139/w10-044.

Manib, M., Zahra, M.K., Abdel, A.L., Heggo, A. 1986. Role of silicate bacteria in releasing $\mathrm{K}$ and $\mathrm{Si}$ from biotite and orthoclase. In Soil biology and Conservation of the Biosphere, ed. Szegi J. pp. 733-743, Budapest: Akademiai Kiado.

Maurya, B.R., Meena, V.S., Meena, O.P. 2014. Influence of inceptisol and alfisol's Potassium Solubilizing Bacteria. KSB. isolates on release of $\mathrm{K}$ from waste mica VEGETOS 27(1): 181187.

Meena, V.S., Bahadur, I., Maurya, B.R., Kumar, A., Meena, R.K., Meena, S.K., Verma, J.P. 2016. PotassiumSolubilizing Microorganism in Evergreen Agriculture: An Overview. page 1-20. In V.S. Meena et al. (eds.), Potassium Solubilizing Microorganisms for Sustainable Agriculture, Springer India.

Meena, V.S., Maurya, B.R., Verma, J.P. 2014. Does a rhizospheric microorganism enhance $\mathrm{K}^{+}$availability 
in agricultural soils? Microbiol. Res., 169: 337-347

Ortiz-Santana, B., Lindner, D.L., Miettinen, O., Justo, A., Hibbett, D.S. 2013. A phylogenetic overview of the antrodia clade. Basidiomycota, Polyporales). Mycologia, 105(6): 1391-1411. doi: 10.3852/13-051.

Page, M.J., Di Cera, E. 2006. Role of $\mathrm{Na}^{+}$and $\mathrm{K}^{+}$in enzyme function. Physiol. Rev., 86: 1049-1092.

Parmar, P,. Sindhu, S.S. 2013. Potassium solubilization by rhizosphere bacteria: influence of nutritional and environmental conditions. J. Microbiol. Res., $\quad 3(1): \quad 25-31 \quad$ DOI: 10.5923/j.microbiology.20130301.04

Pathak, H., Mohanty, S., Jain, N., Bhatia, N. 2010. Nitrogen, phosphorus, and potassium budgets in Indian agriculture. Nutr. Cycl. Agroecosyst., 86: 287-299.

Pinruan, U., Rungjindamai, N., Choeyklin, R., Lumyong, S., Hyde, K.D., Gareth Jones, E.B. 2010. Occurrence and diversity of basidiomycetous endophytes from the oil palm, Elaeis guineensis in Thailand. Fungal Divers 41: 71-88 DOI 10.1007/s 13225-010-0029-1

Prajapati, K., Sharma, M.C., Modi, H.A. 2013. Growth promoting effect of potassium solubilizing Microorganisms on okra. Abelmoscus Esculantus). Int. J. Agric. Sci. Res., 3(1): 181-188.

Rungjindamai, N., Pinruan, U., Choeyklin, R., Hattori, T., Jones, E.B.G. 2008. Molecular characterization of basidiomycetous endophytes isolated from leaves, rachis and petioles of the oil palm, Elaeis guineensis, in Thailand. Fungal Diversity, 33: 139-161

Setiawati, T.C., Mutmainnah, L. 2016. Solubilization of potassium containing mineral by microorganisms from sugarcane rhizosphere. Agric. Agric. Sci. Procedia, 9: 108-117 doi: 10.1016/j.aaspro.2016.02.134.

Sharma, A., Shankhdhar, D., Shankhdhar, S.C. 2016. Potassium-solubilizing microorganisms: Mechanism and their role in potassium solubilization and uptake. page 203-219 In V.S. Meena et al.. eds.), Potassium Solubilizing Microorganisms for Sustainable Agriculture, Springer India.

Supanjani, H.H.S., Jung, J.S., Lee, K.D. 2006. Rock phosphate-potassium and rocksolubilising bacteria as alternative, sustainable fertilizers. Agron Sustain Dev., 26: 233-240

Tamura, K., Stecher, G., Peterson, D., Filipski, A., Kumar, S. 2013. MEGA6: Molecular evolutionary genetics analysis version 6.0. Mol. Biol. Evol., 30: 2725-2729.

Tan, Z.X., Lal, R. Wiebe, K.D. 2005. Global soil nutrient depletion and yield reduction. J. Sustain Agr., 26(1): 123146.

Zhang, C., Kong, F. 2014. Isolation and identification of potassium-solubilizing bacteria from tobacco rhizospheric soil and their effect on tobacco plants. Appl. Soil Ecol., 82: 18-25.

\section{How to cite this article:}

Ramesh Chand Kasana, Nav Raten Panwar, Uday Burman, Chandra Bhushan Pandey and Praveen Kumar. 2017. Isolation and Identification of Two Potassium Solubilizing Fungi from Arid Soil. Int.J.Curr.Microbiol.App.Sci. 6(3): 1752-1762. doi: https://doi.org/10.20546/ijcmas.2017.603.201 